九州大学学術情報リポジトリ

Kyushu University Institutional Repository

\title{
Treatment and Regeneration of Nano-scale Zero- valent Iron Spent in Water Remediation
}

Khalil, Ahmed M.E.

Department of Earth System Science and Technology, Interdisciplinary Graduate School of

Engineering Sciences, Kyushu University

Eljamal, Osama

Department of Earth System Science and Technology, Interdisciplinary Graduate School of Engineering Sciences, Kyushu University

El jamal, Ramadan

Department of Earth System Science and Technology, Interdisciplinary Graduate School of Engineering Sciences, Kyushu University

Sugihara, Yuji

Department of Earth System Science and Technology, Interdisciplinary Graduate School of Engineering Sciences, Kyushu University

他

https://doi.org/10.5109/1808449

出版情報：Evergreen. 4 (1)，pp.21-28，2017-03. 九州大学グリーンアジア国際リーダー教育センター バージョン：

権利関係 : 


\title{
Treatment and Regeneration of Nano-scale Zero-valent Iron Spent in Water Remediation
}

\author{
Ahmed M.E. Khalil, Osama Eljamal*, Ramadan Eljamal, Yuji Sugihara, \\ Nobuhiro Matsunaga \\ Department of Earth System Science and Technology, Interdisciplinary Graduate School of Engineering \\ Sciences, Kyushu University, 6-1 Kasuga-Koen Kasuga, Fukuoka 816-8580, Japan \\ * Corresponding author. Tel/Fax: +81 92583 8387, \\ E-mail: osama-eljamal@kyudai.jp
}

(Received December 21, 2016; accepted January 23, 2017).

\begin{abstract}
Nano-scale zero-valent iron (nZVI) has shown its promising treatment technique to decontaminate nitrate from water. However, research reports lack the treatment and regeneration of the spent reagent from the treatment process. This research utilized different derivatives of nZVIs in the purpose of nitrate treatment in its aqueous solution to show their different reactivities in applied batch experiments. Selected nanoparticles were investigated via transmission electron microscopy, surface characterization analyzer, X-ray diffraction and laser-scattering particle size analyzer. The fresh synthesized nZVI had the highest performance with complete nitrate removal within 60 min. Treated nZVI succeeded to regain the lost reactivity of aged nZVI and boosted its removal efficiency 10 times. On the other hand, the regenerated nZVI, recovered from spent synthesized nanoparticles, regained full and complete removal efficiency of nitrate, the same as the synthesized nZVI. The obtained result gives a great competitiveness of nZVI reagent to treat nitrate against any other treatment technology.
\end{abstract}

Keywords: nitrate removal, nano-scale zero-valent iron, regeneration.

\section{Introduction}

Zero valent iron, especially nano-scale zero-valent iron (nZVI), has shown its high reactivity and active performance in the removal of nitrate via chemical reduction methods. The ZVI reagent can remove nitrate from water through a reduction process illustrated in several research reports ${ }^{1-8}$, which were conducted within the last three decades. According to these studies, iron undergoes oxidation-reduction reaction and reduces nitrate into ammonia, nitrite, and nitrogen at relative quantities depending on the applied reaction conditions ${ }^{7,9}$, ${ }^{10)}$. Also, nZVI was revealed to be the research spotlight and trend for numerous forthcoming and previous studies $^{1-6,11,12)}$ owing to its smaller particle size and higher specific surface area than that of micro-scale (m)ZVI. This resulted in high reaction kinetic rates, which shortened the time to reach higher conversion/removal efficiency that can reach 13.9 times greater than that of $\mathrm{ZZVI}^{13,}{ }^{14)}$. In general, nZVI can be applied in the treatment of wastewaters in lower dosage with a higher cost effectiveness and easier operation ${ }^{15)}$, leading to a higher reactivity compared to that of mZVI.

The investigated contaminant in this study is nitrate, which is known for its hazardous nature and various removal processes that can deal with it. Nitrate is a non- point source contaminant generated as a waste from industrial wastewaters, nitrogenous fertilizers, septic system waste, agricultural runoff and so forth. Nitrate can contaminate groundwater resulting in a polluted plume in the shallow groundwater table that provides the drinking water supply to residents of some rural areas. This pollutant is responsible for different types of diseases such as liver damage, cancer, blue baby syndrome infection, etc. ${ }^{16,17)}$ In addition to its human health problems, it causes environmental problems such as eutrophication ${ }^{18)}$. For these previous reasons, huge environmental entities, such as WHO (World health organization), EPA (Environmental Protection Agency) along with the environmental quality standards for human health in Japan , have set the guideline of the maximum threshold of nitrate to be $11.3^{19)}$ and $10 \mathrm{mg} \mathrm{NO}-\mathrm{N} / \mathrm{L}^{20,21)}$ for drinking water, respectively. That is why many efforts were carried out in applying a suitable treatment process of nitrate using biological or physicochemical processes. Most of these processes suffer different types of drawbacks such as slow and incomplete reaction along with generating soluble microbial products and excessive biomass in case of the biological denitrification ${ }^{22)}$, and frequent regeneration of the media, generation of secondary brine waste and relatively high cost along with the generation of a secondary waste stream in case of 
reverse osmosis and ion exchange technologies ${ }^{23,}$ 24). Adsorbents can be applied for nitrate removal; however, this process is sensitive to $\mathrm{pH}$ changes and has a disposal problem of the spent adsorbent ${ }^{25}$. While the chemical reduction methods are characterized by its high efficacy, removal efficiency and fast kinetic rates ${ }^{2}$. However, this method faced some problems, especially when applying nZVI, which are discussed in our study.

Nano-scale zero-valent iron $\left(\mathrm{n}-\mathrm{Fe}^{0}\right)$ is not a stable form of iron. It can slowly oxidize with air and/or water to its (hydr)oxides with increasing its oxidation number and valences $\left(\mathrm{Fe}^{2+}, \mathrm{Fe}^{3+}\right)$. By this way, nZVI particles' reactivity collapses by passing of time ${ }^{26,27)}$. So a lot of care and concern should be directed to the method of storage of nZVI. In addition, it is important to emphasize on this deactivation behavior by comparing nitrate removal profiles or kinetics to that of fresh nZVI synthesized at optimum synthesis (of chemical emulsion reduction method) conditions so far. The morphology of nZVI particle states that they have core-shell structure. The core is composed of $\mathrm{Fe}^{0}$ whereas the shell side contains two layers of iron (II, III) oxides/hydroxides $(\mathrm{FeO}(\mathrm{OH}))^{26)}$. The shell layer gets enlarged by oxidation slowly with air in case of incautious storage or rapidly in case of nitrate reduction process. Treatment and regeneration processes should be applied in the two cases, respectively. The reason of application is that the primary step of nitrate reduction is its sorption in the shell layer until reaching the core at which the reduction occurs. The thick layer acts as a resisting barrier for nitrate diffusion and electrons transfer to the core resulting in a lower removal performance. By using the treatment method, the thick shell layer is partially dissolved for the purpose of reactivating nZVI particles and regaining reactivity. This method was indirectly mentioned and reported by a few researches as a sort of washing to clean the surface ${ }^{26)}$. The acid treatment method had been applied to aged nZVI purchased since one year from usage in batch experiments. In the other case, the regeneration method targets reviving $\mathrm{Fe}^{0}$ and reconverting spent iron (oxides/hydroxides) in the enlarged thicker shell layer to fresh nZVI. This regeneration process is employed to regain reactivity of spent synthesized nZVI.

According to the authors' acquired knowledge, the literature lacks investigation of this topic related to the study of the reactivity of nZVI towards removal of nitrate from water in different states of nZVI, which are aged (denoted as A-nZVI), treated (T-nZVI), fresh synthesized (S-nZVI) and recovered/regenerated (R-nZVI). This study compares the performances (and difference in reactivity) of these four types in nitrate removal process. The success of treatment and regeneration processes can add benefits and strength points of applying the nZVI technology for contaminated water and wastewater remediation systems.

\section{Materials and Methods}

\subsection{Chemical reagents}

This work utilized sodium borohydride $\left(\mathrm{NaBH}_{4}\right.$, $>98.0 \%$, Sigma-Aldrich Inc., USA), ferric chloride hexahydrate $\left(\mathrm{FeCl}_{3} .6 \mathrm{H}_{2} \mathrm{O},>99.0 \%\right.$, Junsei Chemical Co., Japan) and ethanol $\left(\mathrm{C}_{2} \mathrm{H}_{5} \mathrm{OH}, 99.5 \%\right.$, Wako Co., Japan) in order to synthesize nano-scale zero-valent iron (S-nZVI). The nitrate reactant stock solution was made from dissolving sodium nitrate $\left(\mathrm{NaNO}_{3},>99.0 \%\right.$, Wako Co., Japan) in deionized water (DW filtered with Milli-Q purifier at $18.2 \mathrm{M} \Omega \cdot \mathrm{cm}, 25^{\circ} \mathrm{C}$ ). The $\mathrm{pH}$ was adjusted using sodium hydroxide ( $\mathrm{NaOH},>93 \%$, Wako Co., Japan), hydrochloric acid (HCl, 35-37\%, Wako Co., Japan), and $\mathrm{pH}$ buffer solution (Sansyo Co., Japan). A-nZVI is a commercial nano-scale zero-valent iron (Nano Iron Co., Czech) procured one year before using in batch experiments. In this case, $\mathrm{HCl}$ was applied to treat both AnZVI and spent S-nZVI at different conditions. Nitrogen gas was used to get rid of the dissolved oxygen in all prepared solutions and synthesis, treatment and regeneration processes (set under anoxic conditions) by purging for $20 \mathrm{~min}$.

\subsection{T-nZVI preparation}

The acid treatment/washing process was applied to the surface of A-nZVI using $0.1 \mathrm{M} \mathrm{HCl}$. An amount of 10 grams of the commercial iron was introduced to $250 \mathrm{~mL}$ of $\mathrm{HCl}$ solution in $300 \mathrm{~mL}$ Erlenmeyer (conical glass) flask, and then the whole produced slurry was placed on a shaker adjusted at $200 \mathrm{rpm}$ (reciprocating motion) for $1 \mathrm{~h}$. After shaking, filtration process took place then the obtained wet solids were washed with $200 \mathrm{~mL}$ of deoxygenated DW and $100 \mathrm{~mL}$ absolute ethanol numerous times in order to clean the surface of nanoparticles from any acid traces. The filtered solids were anaerobically dried prior to batch experimental processing.

\subsection{S-nZVI production}

The synthesis process of nZVI was carried out in fourneck glass of $500 \mathrm{~mL}$ volume by the drop-wise addition sodium borohydride reductant solution $\left(\mathrm{NaBH}_{4}, 20 \mathrm{~g} / \mathrm{L}\right)$ to hydrated ferric chloride precursor solution $\left(\mathrm{FeCl}_{3} \cdot 6 \mathrm{H}_{2} \mathrm{O}\right.$, $20 \mathrm{~g} / \mathrm{L}$ ) with equal volume amounts via tubing pump (RP1000, EYELA, Tokyo Rikakikai Co.) at flow rate $1 \mathrm{~L} / \mathrm{h}$. This synthesis process is illustrated more clearly in Figure 1 in which the following reduction reaction occurred to obtain S-nZVI ${ }^{28)}$ :

$4 \mathrm{Fe}^{3+}+3 \mathrm{BH}_{4}^{-}+9 \mathrm{H}_{2} \mathrm{O} \rightarrow 4 \mathrm{Fe}^{0}+3 \mathrm{H}_{2} \mathrm{BO}_{3}^{-}+12 \mathrm{H}^{+}+$ $6 \mathrm{H}_{2}$

The synthesis process conditions were carefully been selected at optimum values based on our previous studies $1,2)$ and other research reports ${ }^{28-30)}$. The resulting reaction mixture was vigorously stirred at $250 \mathrm{rpm}$ and its temperature was contained at $25 \pm 0.5^{\circ} \mathrm{C}$ by the means of water bath. The reaction was left for 20 min after the full injection of the reductant solution to check the completion of the reaction. When the time was up, the produced black slurry was washed with DW (>200 ml/g) and anhydrous ethanol two times, vacuum-filtered and then anaerobically 
dried. The fresh S-nZVI was obtained at 1 gram of dry mass, which was used immediately in nitrate removal batch experiments.

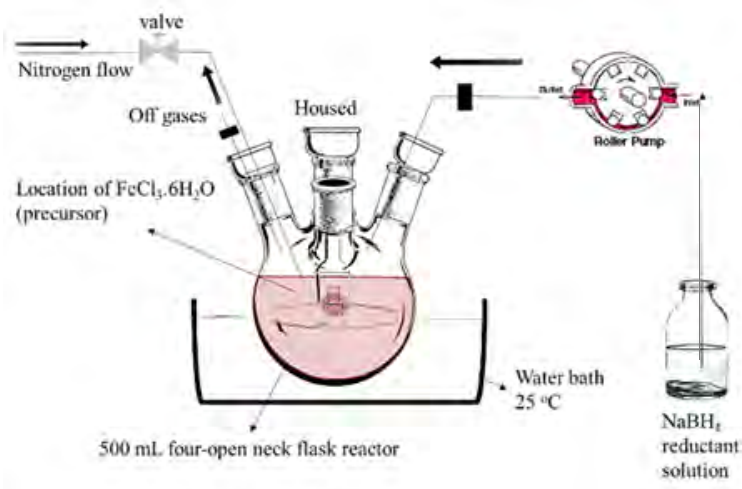

Figure 1: Schematic installation of nZVI synthesis process.

\subsection{R-nZVI acquirement}

The R-NZVI was prepared by dissolving the spent SnZVI, which was collected and filtered after spending in nitrate decontamination experiments, in $\mathrm{HCl}$ solution. The method is based on the following chemical reaction equation (no.3) by the dissolution of the spent magnetite $\left(\mathrm{Fe}_{3} \mathrm{O}_{4}\right)$ resulting from iron oxidation in a hydrochloric solution ${ }^{2,31)}$ :

$\mathrm{NO}_{3}^{-}+3 \mathrm{Fe}^{0}+3 \mathrm{H}_{2} \mathrm{O} \rightarrow \mathrm{Fe}_{3} \mathrm{O}_{4}+\mathrm{NH}_{4}^{+}+2 \mathrm{OH}^{-}$

$\mathrm{Fe}_{3} \mathrm{O}_{4}(s)+8 \mathrm{HCl}$ (aq.) $\rightarrow \mathrm{FeCl}_{2}($ aq. $)+$

$\mathrm{FeCl}_{3}$ (aq.) $+4 \mathrm{H}_{2} \mathrm{O}$

It involves the reconversion of oxidized iron compounds to iron chlorides, which can participate again as a precursor in a regenerating synthesis process with $\mathrm{NaBH}_{4}$ reductant to produce R-nZVI. However, executing the reaction at stoichiometric amounts is slow but beneficial in preventing any excess of acid solution to react with $\mathrm{NaBH}_{4}$ during the regeneration process and waste some of the reductant concentration. Also another problem exists that of converting the whole ferrous chloride to ferric chloride, which is more effective and has faster kinetic rates in reduction with $\mathrm{NaBH}_{4}$ due to the higher number of electron transferred. The process of oxidation of ferrous to ferric ion can be full-filled using oxidizing agent, such as air, hydrogen peroxide, potassium permanganate, etc. In this study, the spent nano iron was treated with stoichiometric amount of $0.5 \mathrm{M} \mathrm{HCl}$ in 300 $\mathrm{mL}$ Erlenmeyer (conical glass) flask under continuous magnetic stirring and continuous flow of air for $20 \mathrm{~h}$. Hydrogen peroxide solution can greatly reduce the oxidation time, but an effective optimization process is needed to find the optimum conditions under a safe environment. The preliminary experiments showed complete dissolution of spent iron compounds in $\mathrm{HCl}$ solution in less than $2 \mathrm{~h}$, but the obtained colorless solution participated in the regeneration process then in batch experiments to recover a low efficiency of nitrate removal. Whereas the oxidized mixture of orange color (after longer time) was the treated spent iron that entered the regeneration process with $\mathrm{NaBH}_{4}$. In this method, the original S-nZVI was prepared with half-original amount (half conc. at $10 \mathrm{~g} / \mathrm{L}$ and same volume) of $\mathrm{NaBH}_{4}$ reductant and then the other half was used in the regeneration process. Both S-nZVI, synthesized at half reductant amount, and R-nZVI were handled after the reaction in the same way as mention in section "S-nZVI production” then they were utilized in batch experiments.

\subsection{Batch experiments}

Nitrate removal performance was evaluated through executing a main batch experiment in $500 \mathrm{~mL}$ four-neck glass flask by applying dosage of $2 \mathrm{~g} / \mathrm{L}$ of nZVI in a 100 $\mathrm{mg} / \mathrm{L}$ of nitrate solution. The nitrate solution was stirred with nZVI reagent (as A-nZVI, T-nZVI, S-nZVI or R$\mathrm{nZVI}$ ) at $250 \mathrm{rpm}$, maintained at $25 \pm 0.5^{\circ} \mathrm{C}$ using a water bath for a maximum duration of $480 \mathrm{~min}$ and kept under anoxic condition using a continuous flow of nitrogen gas. The whole system of experiment was closed by using different plugs with one or two holes. The batch configuration was set up to monitor $\mathrm{pH}$, ORP, concentrations of samples, volume of gas collected, and concentration of stripped ammonia. Samples of $5 \mathrm{~mL}$ were withdrawn at certain given time intervals then filtered through a $0.22 \mu \mathrm{m}$ membrane, and then analyzed for numerous components (nitrate, ammonia, nitrite, total nitrogen, ferrous, ferric and total iron ions). The vent gas from the flask was directed to absorb in $100 \mathrm{~mL}(0.1 \mathrm{M})$ acidic solution in a $200 \mathrm{~mL}$ beaker for the analysis of the stripped ammonia gas. An inverted graduated cylinder full of acidic solution (supported by a stand) was used in one batch experiment, in which no nitrogen purging was applied, in order to collect nitrogen gas (by product) produced from nitrate reduction above the liquid level inside it. Most of batch experiments were performed in doubles to check on the reproducibility of results.

\subsection{Analytical methods}

The analytical process was divided into two main categories: the characterization of the nanoparticles and determination of samples composition (or concentrations). The nanoparticles of selected types of nZVI were investigated for their morphology using transmission electron microscopy (TEM, JEM-ARM 200F, JEOL Co., Japan), for its particle size using laser scattering particle size analyzer (SALD-2300, Shimadzu Co., japan), for specific surface area determined by characterization surface analyzer (Micromeritics 3Flex, USA) and for crystallinity depicted by X-ray diffraction analysis (XRD, TTR, Rigaku, Tokyo, Japan) using $\mathrm{Cu} \mathrm{K} \alpha$ radiation ( $\lambda=$ $1.5418 \AA$ ) operating scanning range from $3^{\circ}$ to $90^{\circ}$ at speed of $2^{\circ} \mathrm{min}^{-1}$. Whereas the samples of batch experiments were colorimetrically analyzed for determining the concentrations of different nitrogen and iron compounds using UV-vis spectrophotometer (DR 3900, HACH co., USA). Nitrate, nitrite and ammonia concentrations were measured using dimethylphenol 
method at $345 \mathrm{~nm}$, USEPA diazotization method at 515 $\mathrm{nm}$ and salicylate method at $690 \mathrm{~nm}$, respectively. Concentration of phosphate (as expressed in phosphorus) was detected via USEPA PhosVer 3 (ascorbic acid method) at $880 \mathrm{~nm}$. Ferrous and total iron concentrations were obtained using 1, 10-phenanthroline method at 510 $\mathrm{nm}$ and TPTZ method (2,4,6-tri(2-pyridinyl)-1,3,5triazine) at $590 \mathrm{~nm}$, respectively ${ }^{32,33)}$.

\section{Results and discussion}

\subsection{Characterization of nZVIs}

The characterization results of both A-nZVI and SnZVI showed high degree of agglomeration as indicated in TEM images of Figure 2. Figures 2i and 2iii showed the morphology of A-nZVI particles, and Figures 2ii, and 2iv represented that of S-nZVI particles. The magnetic nature of these nanoparticles combines them together to form necklace-like structures, which agrees with the observations of different reports ${ }^{14,34)}$. The shell layer of iron nanoparticle can be distinguished from the core area as it appears in a brighter color justifying the presence of lighter atomic masses $(\mathrm{Fe}+\mathrm{O})$. Figure 2iii and 2iv presents a close observation at resolution of $50 \mathrm{~nm}$ that clearly shows the core-shell structure, especially the thicker shell layer of A-nZVI particle compared to that of S-nZVI particle. This obviously reflects the effect of storage time and conditions on the structure and morphology of nZVI.
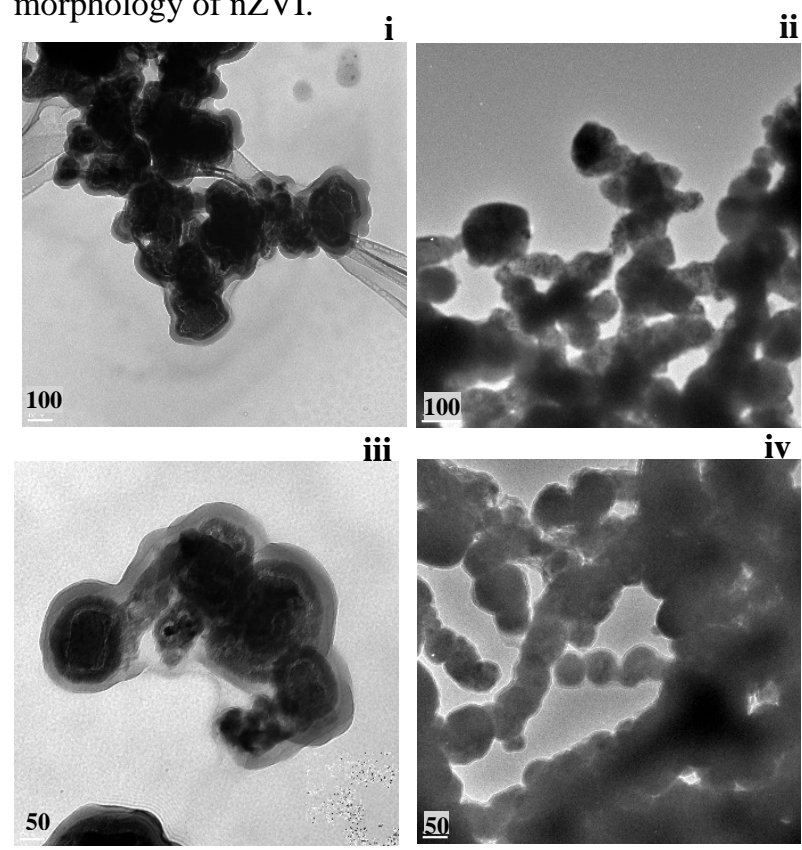

Figure 2: TEM images of A-nZVI (i, iii) and S-nZVI (ii, iv) at different resolutions (100 and 50 nm, respectively).

The particle size distribution was obtained using laser scattering particle size analysis under an internal sonication condition for both A-nZVI and S-nZVI (appeared in the graph of Figure 3). The average aggregated particle sizes of both A-nZVI and S-nZVI were measured to be $1.993 \mu \mathrm{m}$ and $42 \mathrm{~nm}$, respectively. These results hypothetically match up with the observed particle sizes of TEM images (in Figures 2iii and 2iv) showing the particle sizes of A-nZVI more than $50 \mathrm{~nm}$ and that of S-nZVI less than/around $50 \mathrm{~nm}$. However, the results of particle sizes observed in TEM images are more related to a single particle size than an aggregated size, especially at high resolution power. The particle size distribution of the synthesized nanoparticles seems narrower than the distribution of the aged nanoparticles (shown in Figure 3), adding that the aggregate particle size is smaller. Although the S-nZVI has finer particle size than A-nZVI which increases its tendency towards agglomeration, but the aging period was sufficient to build up these agglomerations. This reflected upon the lower Brunauer-Emmett-Teller (BET) specific surface area value of A-nZVI particles (of $14.5 \mathrm{~m}^{2} / \mathrm{g}$ ) compared to the value of BET specific surface area of fresh S-nZVI (62 $\mathrm{m}^{2} / \mathrm{g}$ ) obtained at optimum synthesis conditions.
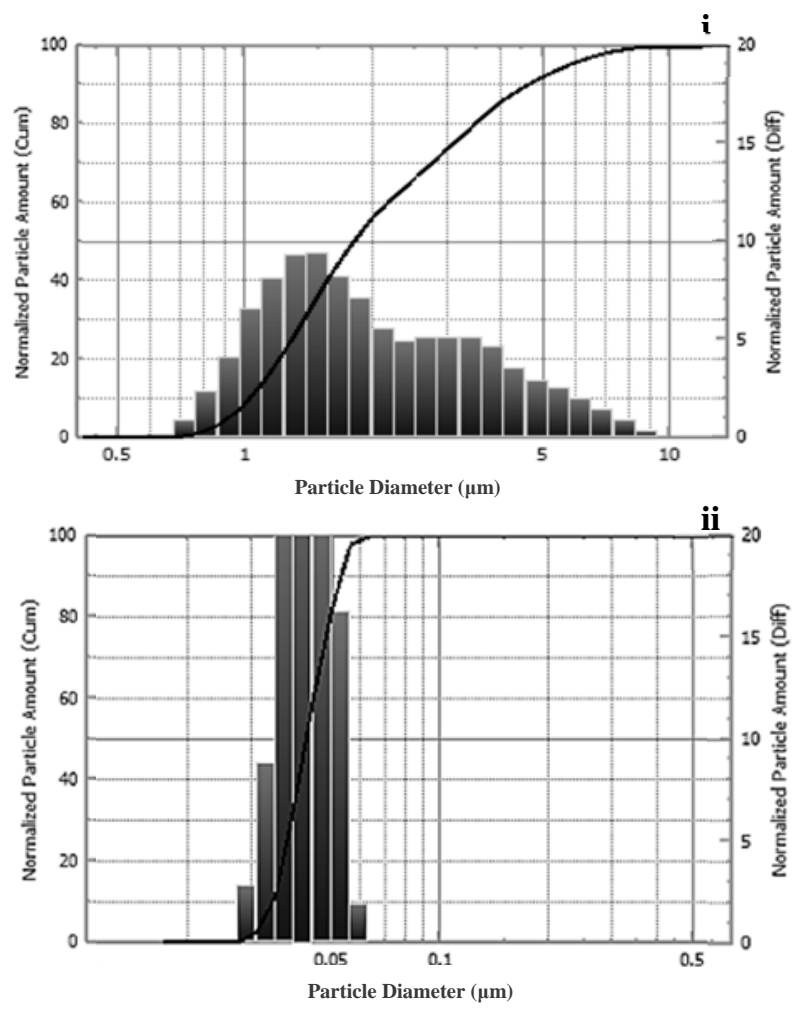

Figure 3: Particle size distribution of i) A-nZVI and ii) S-nZVI.

The XRD patterns of both aged and fresh synthesized nanoparticles are shown in Figure 4. These patterns are semi-identical detecting zero valent iron $\left(\mathrm{Fe}^{0}\right)$ at its major deflection angle $2 \theta$ of $44.8^{\circ}$ and other angle $82.6^{\circ}$. The XRD analysis did not detect iron oxides attributed to their relative small amounts and low degree of crystallinity. The higher intensity peak of A-nZVI in XRD pattern indicates a more crystalline structure than that of S-nZVI. The incomplete drying process of S-nZVI particles was the reason of its lower crystallinity to prevent probabilities of iron oxidation. 


\subsection{The mechanism of nitrate reduction by nZVI}

The mechanism of nitrate reduction was carefully scrutinized in order to describe the removal process for TnZVI and S-nZVI only (as A-nZVI had a very low reactivity and R-nZVI had a close performance to the SnZVI, which are shown in the forthcoming section). Spectrophotometric analysis results (revealed in Figure 5) showed that ammonia $\left(\mathrm{NH}_{4}^{+}\right)$was detected in high concentrations indicating being the main product. Nitrite $\left(\mathrm{NO}_{2}^{-}\right)$was also found at a relatively higher concentration (around $5 \mathrm{mg} / \mathrm{L}$ produced from utilizing S-nZVI) at the initial period of the batch experiment, which was reduced and eliminated throughout the course of the treatment reaction. Therefore, it is obvious that nitrate reduction mechanism involves reducing nitrate into nitrite and ammonia, the former product was then consumed to produce ammonia and nitrogen. According to this discussion, the following reaction mechanism was proposed that match up with our previous reports and other studies ${ }^{2,4)}$ :

$$
\begin{aligned}
& 4 \mathrm{Fe}^{0}+\mathrm{NO}_{3}^{-}+10 \mathrm{H}^{+} \rightarrow 4 \mathrm{Fe}^{2+}+\mathrm{NH}_{4}^{+}+3 \mathrm{H}_{2} \mathrm{O} \\
& \mathrm{Fe}^{0}+\mathrm{NO}_{3}^{-}+2 \mathrm{H}^{+} \rightarrow \mathrm{Fe}^{2+}+\mathrm{H}_{2} \mathrm{O}+\mathrm{NO}_{2}^{-} \\
& 3 \mathrm{Fe}^{0}+\mathrm{NO}_{2}^{-}+8 \mathrm{H}^{+} \rightarrow 3 \mathrm{Fe}^{2+}+2 \mathrm{H}_{2} \mathrm{O}+\mathrm{NH}_{4}^{+} \\
& 3 \mathrm{Fe}^{0}+2 \mathrm{NO}_{2}^{-}+8 \mathrm{H}^{+} \rightarrow 3 \mathrm{Fe}^{2+}+4 \mathrm{H}_{2} \mathrm{O}+\mathrm{N}_{2}
\end{aligned}
$$

As indicated by the proposed reaction mechanism, ammonia should have the largest concentration value followed up with nitrite then nitrogen concentrations. The assumed mechanism agrees with the results of analysis in Figure 5 that depicts the concentration profiles of nitrate reduction products.

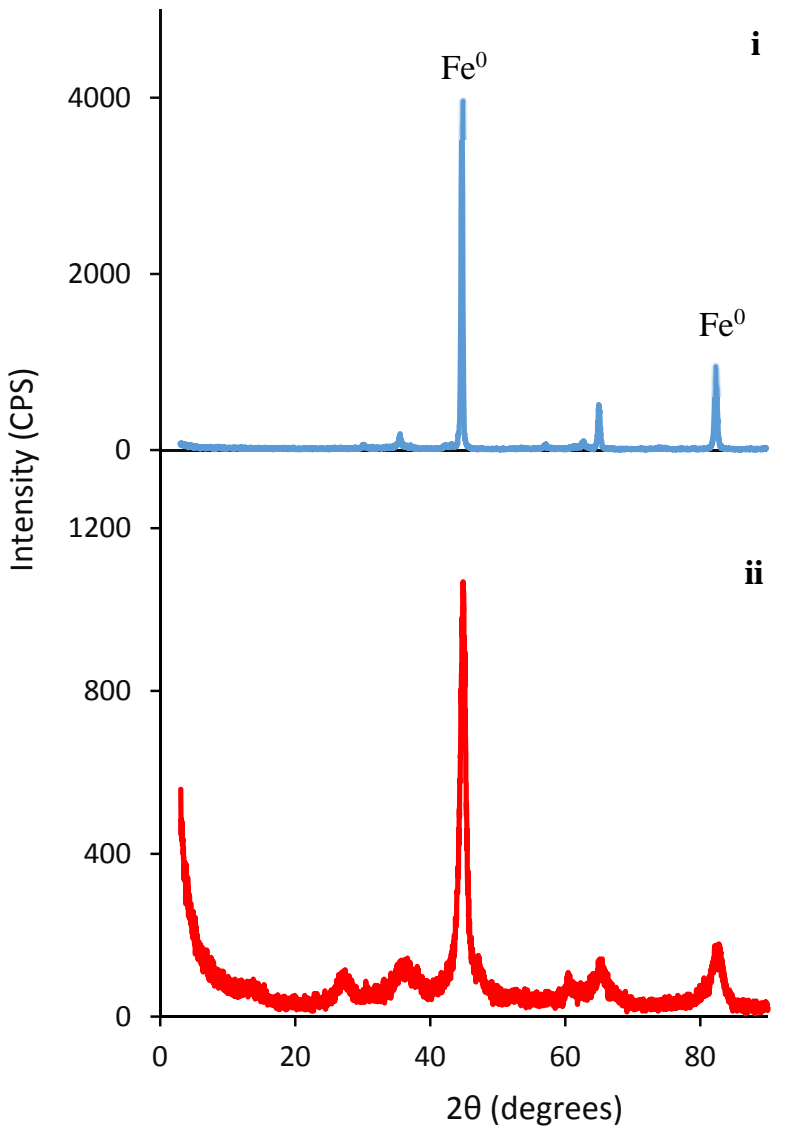

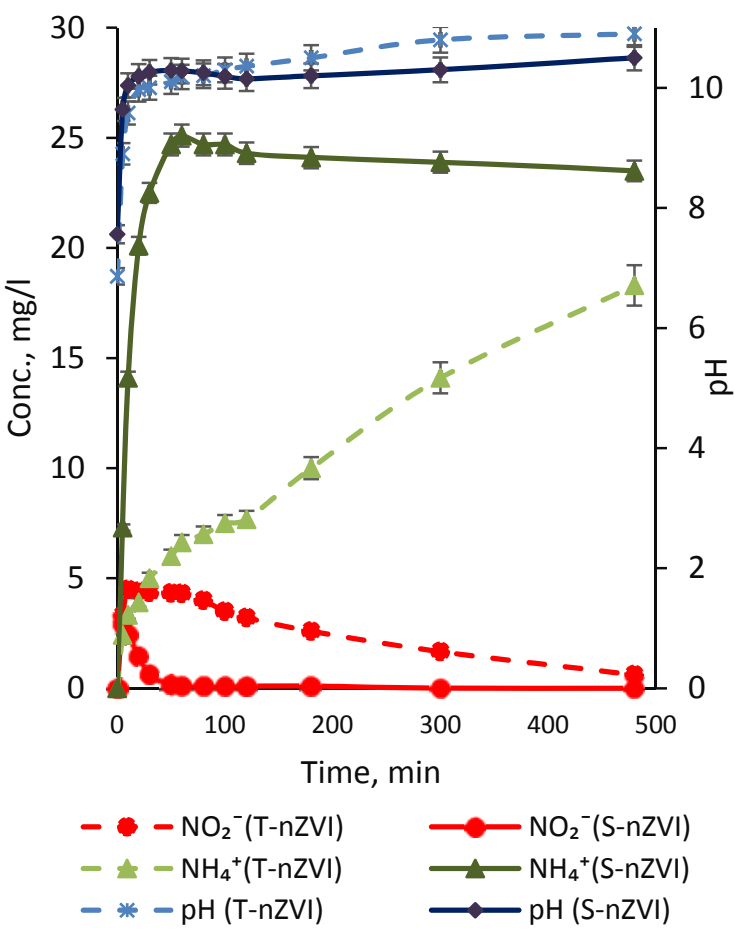

Figure 5: Tracking concentrations of produced nitrogen compounds and $\mathrm{pH}$ from nitrate reduction using T-nZVI and S-nZVI.

The produced ammonia concentration value is an indication of the reactivity of the utilized nanoparticles in the batch process. The highest ammonia production was for the S-nZVI (and R-nZVI) evidencing high reactivity and performance compared to other nZVIs. The nitrite in both cases (S-nZVI and T-nZVI) exhibited the same trend of concentration profiles, which proves that nitrite was consumed in other reactions (Eqn. 6 and 7) to produce ammonia and nitrogen. Ammonia is an unpleasant product, which needs further treatment. However, the high monitored $\mathrm{pH}$ of the solution mixture can strip out ammonia that was collected in a graduated cylinder at 7 $\mathrm{mL}$ volume at NTP, which corresponds, to a total concentration of $\mathrm{NH}_{4}^{+}-\mathrm{N}$ equal to $9.74 \mathrm{mg} \mathrm{N} / \mathrm{L}$ (50\% of total) and the rest was absorbed in water under the inverted graduated cylinder. Also the gas chromatograph (GC 3200, GL Sciences Co., Japan) analysis detected nitrogen gas in that collected gas volume at low concentration (2\%). In addition, the total nitrogen amount of all produced nitrogen compounds was lower than the initial total amount of nitrogen (22.58 mg N/L corresponding to 100 $\mathrm{mg}$ nitrate/L) confirming the production of the nitrogen gas. The spent nZVI in nitrate reduction reactions is mainly composed of magnetite $\left(\mathrm{Fe}_{3} \mathrm{O}_{4}\right)$ and $\mathrm{FeO}(\mathrm{OH})$ from depositions and reactions of ferrous and ferric ions (appeared in Eqn. 2) and unreacted $\mathrm{Fe}^{0}$. In addition, Figure 6 presented XRD pattern of the spent nZVI providing a support to the previously mentioned statement regarding the presence of magnetite and iron oxide products.

Figure 4: XRD patterns of i) A-nZVI and ii) S-nZVI. 


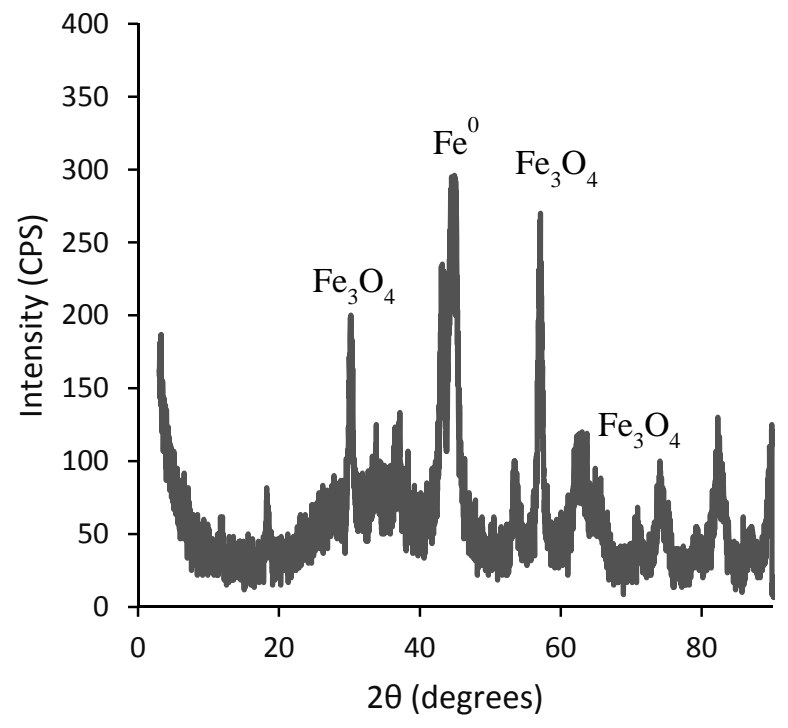

Figure 6: XRD pattern of the spent S-nZVI featuring iron (II, III) oxides.

The spent nZVI from S-nZVI batch experiments was dissolved in dil. $\mathrm{HCl}$ solution and sampled then analyzed for the existence of nitrate remaining, which might be still adsorbed within shell layers. The results indicated that the whole amount of the nitrate was reduced and no adsorbed nitrate was still detected. In general, nitrate reduction mechanism starts with adsorption of nitrate on the shell layer of the iron nanoparticle then followed by the complete chemical reduction to almost all adsorbed amount at the core of zero-valent iron with being this step the controlling step (slowest step) in the whole process. This nitrate reduction step is described by first-order kinetic rate equation ${ }^{2}$.

\subsection{Performance of nZVIs in nitrate removal}

The reactivity of A-nZVI, T-nZVI, S-nZVI and R-nZVI

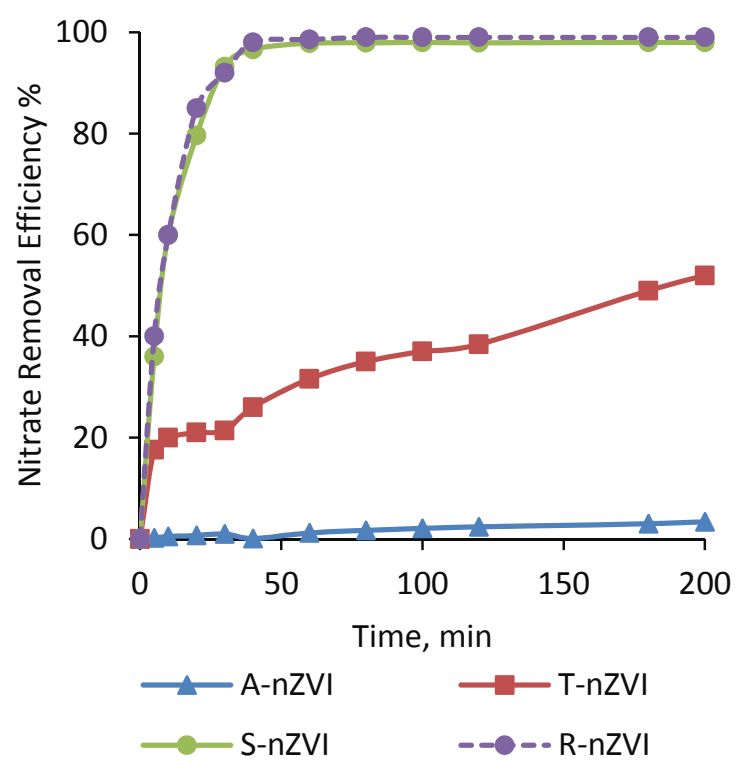

Figure 7: The performance of the four nZVIs in nitrate removal batch experiments. were examined using 1-gram dosage of nZVI and starting with initial concentration $100 \mathrm{mg} \mathrm{NO}_{3}^{-}-\mathrm{N} / \mathrm{L}$ under the same conditions. The profiles of removal efficiency representing their results versus the experimental time are observed in Figure 7 . The removal efficiencies were calculated based on the percentages of the difference in concentrations, between initial concentration and specific concentration at the selected sampling time, referred to (or divided by) the initial concentration of the investigated solution.

It is clear that A-nZVI has the lowest performance and reactivity, which cannot even reach $10 \%$ after 8 h. The effect of aging is crucial on the reactivity of these nanoparticles. Originally, the new commercial nano-iron with its specific BET surface area $\left(25 \mathrm{~m}^{2} / \mathrm{g}\right)$ can give $50 \%$ as a nitrate removal after two hours when equilibrium is achieved. The investigations on its new BET specific surface area after aging was found to be around $15 \mathrm{~m}^{2} / \mathrm{g}$ with about $40 \%$ decrease in surface area available for reaction. Adding that the formation of larger shell layer as referred to TEM images (in Figure 2) of iron (hydr)oxides severely contributed in that drop in reactivity. However, the acid treatment of A-nZVI restored a great portion of the fallen removal efficiency. The T-nZVI succeeded to remove half of the whole nitrate load within $3 \mathrm{~h}$. The dilute acid can dissolve all the iron components, so the molarity of acid and time of treatment are important factor to consider so as to only dissolve a part of a shell layer without consuming the ZVI core. That is why the acid was used at a low molarity and limited time for that purpose.

Regarding the fresh synthesized and regenerated iron nanoparticles, S-nZVI obtained a high efficiency and completely removed the nitrate load after $1 \mathrm{~h}$ of reaction. Surprisingly, R-nZVI performed in almost the same way as that of S-nZVI and achieved a removal efficiency of $100 \%$ within the same period. Also nZVI was regenerated from S-nZVI prepared with half original concentration of sodium borohydride reductant, and the other half was used to regenerate acidified spent S-nZVI. The results of this process are shown in Figure 8. The results are close to that of Figure 7 except for that the removal of S-nZVI at half

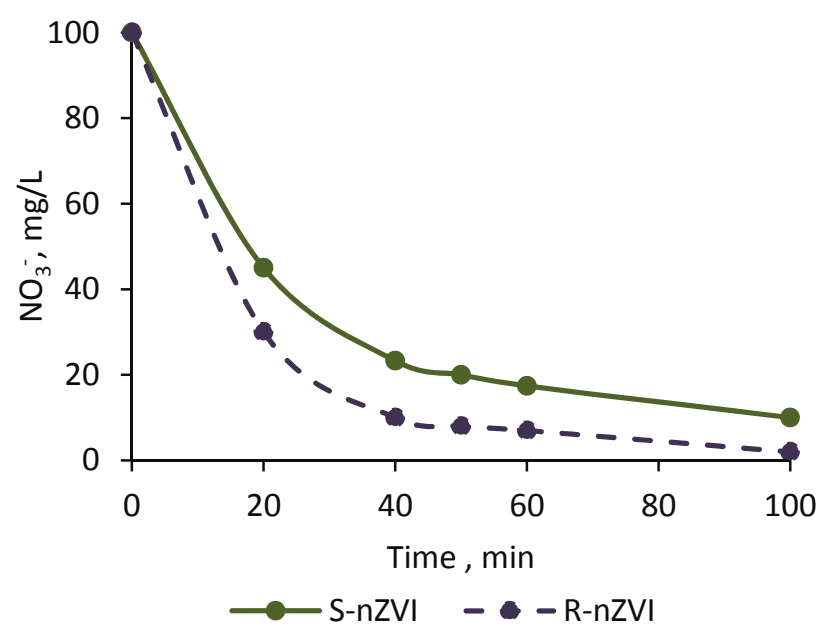

Figure 8: Nitrate concentration profiles resulted from utilizing of S-nZVI and its regenerated nanoparticles R-nZVI (synthesized and regenerated at half reductant concentration) in batch experiments. 
original $\left[\mathrm{NaBH}_{4}\right]$ is being slightly lower than that of SnZVI at full original $\left[\mathrm{NaBH}_{4}\right]$. The correlation between the nitrate removal efficiency (expressing S-nZVI reactivity) and the effect of reductant concentration can be reviewed elsewhere ${ }^{28}$ ), and these results here agree with that relation.

Comparing between results of Figure 8 with Figure 7, there is an indication that the S-nZVI and R-nZVI in Figure 8 can treat approximately double load of nitrate at a summation of $\mathrm{NaBH}_{4}$ amount equal to that used to produce S-nZVI (appeared in Figure 7) at full $\mathrm{NaBH}_{4}$ amount. The only change is the addition of diluted $\mathrm{HCl}$ as a part of regeneration process. The low molarity of $\mathrm{HCl}$ is used for stoichiometric conversion of iron oxides to iron (II, III) chlorides, which is economic but takes a long time for reaction. However, the rate of reaction is clearly increased when applying high molarities of $\mathrm{HCl}$. The problem with this procedure is that the excess $\mathrm{HCl}$ can consume a part of reductant during regeneration process, even neutralizing the excess acid generates salts unfavorable to be found in the synthesis and regeneration processes of nZVI. The bubbling of acidified spent SnZVI with air was not too effective in increasing ferric ions, as indicated by the initial masses of ferrous and ferric ions before bubbling: $0.7 \mathrm{~g} \mathrm{Fe}^{2+}$ and $0.3 \mathrm{~g} \mathrm{Fe}^{3+}$, and after bubbling: $0.53 \mathrm{~g} \mathrm{Fe}^{2+}$ and $0.47 \mathrm{~g} \mathrm{Fe}^{3+}$. However, this did not affect the results to obtain a reactive $\mathrm{R}-\mathrm{nZVI}$. The search on a good oxidant is going on to completely convert $\mathrm{Fe}^{2+}$ to $\mathrm{Fe}^{3+}$ in a shorter time without affecting the efficiency of the regeneration process. It is important to mention that the amount of total iron in the acidified SnZVI was measured to be almost 1 gram (without losses in mass).

In general, the performance of regenerated nanoparticles seems slightly higher than the original synthesized nanoparticles as it appears in Figure 8. This can be attributed to the lower $\mathrm{pH}$ of the entering regenerated solution of ferric chloride ( $\mathrm{pH} 0.9$ ) compared to the $\mathrm{pH}$ of the original ferric chloride solution ( $\mathrm{pH} 2.4)$. The slightly lower $\mathrm{pH}$ solution is capable of dissolving iron (hydr)oxides and decreasing surface passivation of iron as previously mentioned in the treatment process.

\section{Conclusion}

This research investigated the nitrate reduction reactivity and performance of four different types of nZVIs under the same batch experimental conditions. The effect of aging on nZVI was highlighted and found to have a collapsing effect on the reactivity. The nitrate removal efficiency for A-nZVI did not exceed 10\% after a long period of time. Nevertheless, the aged nZVI was treated in an acid treatment process using a dilute $\mathrm{HCl}$ at a controlled and limited treatment time. This kind of washing surface removed portion of shell layer of nZVI particle leaving its surface exposed to the reduction reaction obtaining 50\% removal of nitrate within three hours. While a one hour was sufficient to remove the whole nitrate load on applying the S-nZVI, which was used immediately after synthesis and characterized by its high value of BET-SSA. The spent S-nZVI was not wasted, it was regenerated using a diluted acid and reductant at specific conditions. A regeneration process was applied on the spent to produce R-nZVI which successfully reduced the whole amount of nitrate within the same short period (1h). The regeneration process of nZVI seems to be a promising process, especially for nZVI used in systems resembling pump-and-treat technologies and conventional activated sludge systems, but further optimization of this process should be executed to shorten its time, as this regeneration step of nZVI is a very important topic to be addressed. Summing up, the treatment and regeneration process suggested by this study can be employed to reactivate aged and spent reagent of nZVI particles used in water remediation.

\section{References}

1) A. M. Khalil, O. Eljamal, T. W. Amen, Y. Sugihara and N. Matsunaga, Chem. Eng. J., 309, 349-365 (2017).

2) A. M. Khalil, O. Eljamal, S. Jribi and N. Matsunaga, Chem. Eng. J., 287, 367-380 (2016).

3) D. O’Carroll, B. Sleep, M. Krol, H. Boparai and C. Kocur, Adv. Water Resour., 51, 104-122 (2013).

4) Y.-H. Hwang, D.-G. Kim and H.-S. Shin, J. Hazard. Mater., 185, 1513-1521 (2011).

5) G. C. Yang and H.-L. Lee, Water Res., 39, 884-894 (2005).

6) Y. H. Liou, S.-L. Lo, C.-J. Lin, W. H. Kuan and S. C. Weng, J. Hazard. Mater., 127, 102-110 (2005).

7) C.-P. Huang, H.-W. Wang and P.-C. Chiu, Water Res., 32, 2257-2264 (1998).

8) I. F. Cheng, R. Muftikian, Q. Fernando and N. Korte, Chemosphere, 35, 2689-2695 (1997).

9) L. L. Zawaideh and T. C. Zhang, Water Sci. Technol., 38, 107-115 (1998).

10)D. P. Siantar, C. G. Schreier, C.-S. Chou and M. Reinhard, Water Res., 30, 2315-2322 (1996).

11)J. Zhang, Z. Hao, Z. Zhang, Y. Yang and X. Xu, Process Saf. Environ. Prot., 88, 439-445 (2010).

12)S. Choe, Y.-Y. Chang, K.-Y. Hwang and J. Khim, Chemosphere, 41, 1307-1311 (2000).

13)T. Almeelbi and A. Bezbaruah, J. Nanopart. Res., 14, 1-14 (2012).

14)O. Eljamal, A. M. Khalil, Y. Sugihara and N. Matsunaga, Chem. Eng. J., 293, 225-231 (2016).

15)H. Song and E. R. Carraway, Appl. Catal., B., 78, 5360 (2008).

16)A. Bhatnagar and M. Sillanpää, Chem. Eng. J., 168, 493-504 (2011). 
17)A. Kapoor and T. Viraraghavan, J. Environ. EngASCE, 123, 371-380 (1997).

18) R. F. Follett and J. L. Hatfield, The Scientific World Journal, 1, 920-926 (2001).

19)W.H. Organization, Guidelines for Drinking-Water Quality: Recommendations, 1, World Health Organization, p. 417 (2004).

20)EPA, Basic Information about Nitrate in Drinking Water, [cited 2016/12/1]; Available from: $<$ http://water.epa.gov/drink/contaminants/basicinform ation/nitrate.cfm>.

21)M. JP, Environmental quality standards for water pollution, [cited 2016/12/1]; Available from: $<$ https://www.env.go.jp/en/water/wq/wp.pdf>.

22)Y. Fernández-Nava, E. Maranon, J. Soons and L. Castrillón, Bioresour. Technol., 99, 7976-7981 (2008).

23)J. Schoeman and A. Steyn, Desalination, 155, 15-26 (2003).

24)B.-U. Bae, Y.-H. Jung, W.-W. Han and H.-S. Shin, Water Res., 36, 3330-3340 (2002).

25)Q. H. N. C. C. Feng and W. Hu, Adsorption, 50, 1 (2015).

26)J. Luo, G. Song, J. Liu, G. Qian and Z. P. Xu, J. Colloid Interface Sci., 435, 21-25 (2014).

27)http://www.nanoiron.cz/en/news/136-nzvi-slurryageing-behaviour. Cited 2016/12/1.

28)Y.-H. Hwang, D.-G. Kim and H.-S. Shin, Appl. Catal., B., 105, 144-150 (2011).

29)R. Yuvakkumar, V. Elango, V. Rajendran and N. Kannan, Dig. J. Nanomater. Biostruct, 6, 1771-1776 (2011).

30)H.-C. Song, E. R. CarraWay and Y.-H. Kim, Environ. Eng. Res., 10, 174-180 (2005).

31)R. Rennie, J. Law and J. Daintith, A Dictionary of Chemistry, Oxford University Press, p. 296 (2016).

32)A. D. Eaton, M. A. H. Franson, A. Association and A. Association, Standard Methods for the Examination of Water and Wastewater, American Public Health Association, (2005).

33)W. Fresenius, K. E. Quentin and W. Schneider, Water analysis; a practical guide to physico-chemical, chemical and microbiological water examination and quality assurance, Springer-Verlag, (1988).

34)Y. Zhang, Y. Li, J. Li, L. Hu and X. Zheng, Chem. Eng. J., 171, 526-531 (2011). 